\title{
COSTA DE FIORDES DA PATAGÔNIA CENTRAL, CHILE, MORFOLOGIA SUBMARINA E FÁCIES ACÚSTICAS
}

\author{
Rosemary Vieira ${ }^{1}$ e Jefferson Cardia Simões ${ }^{1,2}$ \\ Recebido em 23 setembro, 2005 / Aceito em 21 fevereiro, 2006 \\ Received on September 23, 2005 / Accepted on February 21, 2006
}

ABSTRACT. This study interprets acoustic sub-bottom profiles and submarine 3D models of some of fjords adjacent to Campo de Hielo Patagónico Sur (Southern Patagonian Icefield), Chile. The overdeepened fjord basins show irregular morphology and distinctive landforms associated with a grounding-line, ice tongues and icebergs sedimentary system. Acoustic reflectors display two main facies: chaotic and laminated, according the internal reflection configuration and the external geometry. The sediments probably were deposited during the Holocene deglaciation, as shown by the visible reflectors of sub-bottom profiler. The geometry of the depocenters and the acoustic reflectors characteristic show evidence of pre-existing topography and bathymetry influence. Due to the great water depths of the fjord basins, terminal margins may have a mix of floating and grounded cliff behaviour, albeit the predominant temperate glacial regime.

Keywords: fjords, submarine morphology, acoustic reflectors, Patagonia, Chile.

RESUMO. Esse estudo interpreta os perfis acústicos de subfundo e modelos 3D submarinos de alguns fiordes adjacentes ao Campo de Gelo Patagônico Sul, Chile. As bacias aprofundadas mostram a morfologia irregular e distintas formas associadas ao sistema sedimentar de zonas de grounding line, de línguas de gelos flutuantes. Refletores acústicos exibem duas fácies principais: caóticas e estratificadas, segundo sua configuração interna e geometria externa. Os sedimentos provavelmente foram depositados durante a deglaciação durante o Holoceno. A geometria dos depocentros e as características dos refletores acústicos mostram evidências da influência da batimetria e da topografia pré-existentes. Devido às grandes profundidades das bacias, as margens terminais podem ter sido um misto de condições flutuantes e aterradas no fundo marinho, embora possa predominar o regime glacial temperado.

Palavras-chave: fiordes, morfologia submarina, refletores acústicos, Patagônia, Chile.

\footnotetext{
${ }^{1}$ Núcleo de Pesquisas Antárticas e Climáticas - NUPAC. Departamento de Geografia, UFRGS, Av. Bento Gonçalves, 9500, prédio 43136, salas 208 e 210 , 91501-970 Porto Alegre, RS, Brasil. Tel: (51) 3316-6341; (51) 3316-7324 - E-mail: rosemary.vieira@ufrgs.br

2E-mail: jefferson.simoes@ufrgs.br
} 


\section{INTRODUÇ̃̃o}

Deglaciação em fiordes produz diversas geoformas e seqüências sedimentares que são registros de processos efetuados nas zonas proximais e distais da margem do gelo (Cofaigh, 1998).

Em ambientes glacimarinhos, isto é, ambientes onde processos ou depósitos envolvem a ação conjunta de geleiras e do mar ou a ação de geleiras em ambiente marinho, estudos mais detaIhados dos processos e de feições morfológicas desenvolvidos no fundo marinho, e em especial, dos fiordes, iniciaram apenas nas últimas duas décadas, estimulados pela disponibilidade de novas ferramentas e técnicas (Stoker et al., 1997). Dentre elas, o método sísmico-acústico tem sido fundamental para os estudos da morfologia do fundo e do subfundo marinho, além de possibilitar mensurações das seqüências estratificadas e dos corpos sedimentares marginais à frente das geleiras.

A costa de fiordes do Chile se estende desde $41^{\circ} \mathrm{S}$ a $55^{\circ} \mathrm{S}$ e é também conhecida como "costa de fiordes da Patagônia". Existem mais de 200 fiordes, dos quais pelo menos 70 deles estão situados na costa interna, enquanto o restante está na costa externa, junto ao oceano Pacífico (Syvitski et al., 1987). Apesar de sua grande extensão, estudos sobre ambientes glacimarinhos não estão tão avançados como em outras regiões do mundo. Além disso, muitos dos processos e controles erosivos e deposicionais que atuam nos fiordes da Patagônia chilena, tanto em suas bacias submarinas como nas partes subaéreas, ainda são desconhecidos e certos tipos de depósitos e sua distribuição são igualmente pouco compreendidos.

Esse trabalho tem por objetivo principal o estudo integrado do ambiente glacimarinho da zona interna da costa de fiordes da Patagônia Central, Chile, com a geomorfologia glacial e a topografia-batimetria submarina, através da interpretação de registros acústicos e de modelos topográficos tridimensionais.

\section{Área de Estudo}

A área de estudo compreende o domínio interno da costa de fiordes chilena, na Patagônia central. As cabeceiras dos fiordes são alimentadas por geleiras de marés que fluem do Campo de Gelo Patagônico Sul (CGPS) (Figura 1). Entende-se por geleira de marés a que termina no ambiente marinho, geralmente sua parte frontal está aterrada no fundo do mar. De suas paredes são descarregados icebergs.

A topografia subaérea é dominada pela cordilheira dos Andes que formou um eixo de alongados campos de gelo que se estendem por mais de $1.800 \mathrm{~km}$, entre $38^{\circ} \mathrm{S}$ e $56^{\circ} \mathrm{S}$. Tais corpos de gelo se encontram sobre platôs intermontanos cercados por cristas de montanhas entre 1.700-2.000 m (Sugden et al., 2002). 0 CGPS é o maior sistema glacial de zonas temperadas no hemisfério sul, e a segunda maior massa de gelo no hemisfério depois da Antártica, com uma extensão de $350 \mathrm{~km}$ e uma largura média de $35 \mathrm{~km}$, constituindo uma área em torno de $13.000 \mathrm{~km}^{2}$ (Casassa et al., 2000). Está constituído por 48 grandes geleiras, e por mais de uma centena de pequenas geleiras de anfiteatro e de vale. Essas geleiras se deslocam da cordilheira dos Andes para 0 Leste e Oeste, geralmente terminando com frentes desprendentes (calving fronts) em lagos (Leste) e em fiordes (Oeste) (Aniya et al., 1996, 1997; Cassasa et al., 2000).

\section{Fiordes}

Fiordes são geralmente profundos, escarpados e localizados em latitudes médias e elevadas (a partir de $42^{\circ}$ no hemisfério sul, e acima dos $43^{\circ}$ no hemisfério norte), os quais foram ou ainda estão sendo escavados ou modificados pelo gelo (Syvitski et al., 1987; Syvitski \& Shaw, 1995). São característicos de regiões montanhosas, as quais em épocas atuais ou em um passado recente abrigaram campos de gelo alimentando geleiras de vale. Por definição, todos os fiordes já foram influenciados pelo gelo durante longos períodos de sua história (Syvitski et al., 1987).

Um dos principais controles do comportamento frontal das geleiras que terminam em fiordes, e a conseqüente produção de geoformas sedimentares subaéreas e submarinas, é a morfologia dos canais, incluindo a topografia e batimetria. Características morfológicas podem ser decisivas para a dinâmica glacial e, conseqüentemente, controlar a quantidade, o tipo e a localização de depósitos sedimentares em um fiorde (Seramur et al., 1997).

\section{MATERIAIS E MÉTODOS}

Foram analisados os registros do perfilador de subfundo $3,5 \mathrm{kHz}$, obtidos durante o cruzeiro Campo de Hielo Sur, em 1995, no navio oceanográfico Vidal Gormaz por iniciativa do Comité Oceanográfico Nacional(CONA - Chile) e realizado pelo Servicio Hidrográfico y Oceanográfico de la Armada de Chile (SHOA). 0 equipamento utilizado foi a ecossonda Edo Western, MODELO $248 \mathrm{E}$, que pode transmitir nas freqüências de 3,5 e $12 \mathrm{kHz}$. No modo perfilador de subfundo é utilizada a freqüência $3,5 \mathrm{kHz}$. Nesse modo 0 amplificador 465A permite que 0 sistema penetre as camadas do subfundo marinho. Os sinais acústicos foram convertidos em sinais elétricos analógicos, que por sua vez foram convertidos em movimentos mecânicos em um registrador eletrográfico modelo 3211.

A resolução dos perfis acústicos depende do ajuste en- 


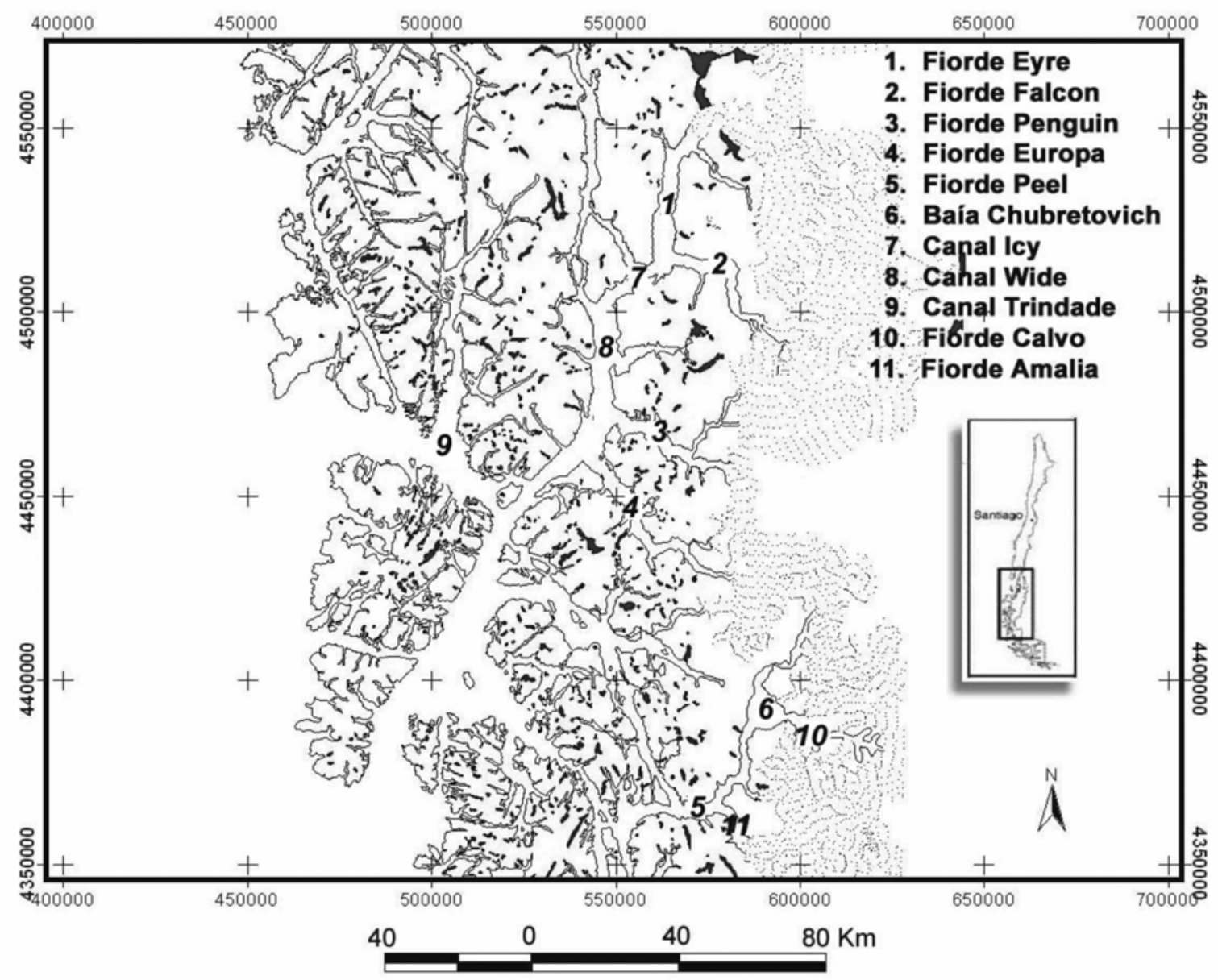

Figura 1 - Costa de fiordes da Patagônia Central, Chile.

tre a freqüência do sinal e a potência de penetração. Para a identificação de ambientes subsuperficiais mais rasos, freqüências próximas a 3,5 kHz são utilizadas. Apesar da freqüência de $12,0 \mathrm{kHz}$ ser muito usada para perfilagem do fundo e de subfundo, esta não consegue penetrar muito nas camadas de sedimentos. Assim, a freqüência 3,5 kHz é capaz de prover bastante informação sobre a estratificação (e.g., presença ou ausência de subfundo, ou migração do subfundo). Além disso, a freqüência de $3,5 \mathrm{kHz}$ exibe mais claramente os sinais de hipérboles produzidos pelas diferentes morfologias do fundo marinho (Damuth, 1980).

Os perfis seguem o eixo longitudinal dos fiordes e canais, e se encontram incompletos em direção à cabeceira dos fiordes em virtude da presença do gelo marinho e do desprendimento de icebergs. A velocidade acústica adotada para o cálculo da profundidade e da espessura dos sedimentos é de $1.500 \mathrm{~m} \mathrm{~s}^{-1}$.
Características acústicas foram empregadas na identificação de distintos ambientes deposicionais, incluindo: (1) grau de intensidade das superfícies refletoras; (2) a configuração da reflexão, classificada em estratificada, caótica e transparente e (3) a geometria externa (Damuth, 1978, 1980; Stocker et al., 1997; Duchesne et al., 2001).

Os fiordes da costa austral do Chile são caracterizados por suas grandes profundidades (> $300 \mathrm{~m}$ ). Essas profundidades criam numerosos problemas: sinais múltiplos, distorções devido aos gradientes de inclinação das vertentes submarinas e ao maior tempo de retorno do sinal. Ao registrar o subfundo com rápidas alterações no gradiente, i.e., ondulações em curtas distâncias, distorções são produzidas, como por exemplo, algumas feições hiperbólicas. Nas zonas próximas às cabeceiras dos fiordes, a baixa profundidade também produz distorções nos registros. Para amenizar esses problemas, ajustes na freqüência e transmissão 
dos sinais foram efetuados de acordo com a batimetria local.

Os registros acústicos foram obtidos em escalas variáveis, calculadas a partir da velocidade do navio, dos tempos anotados e das coordenadas GPS. As escalas verticais variam entre 1:375, 1:750 e 1:1.500. Assim, 0 exagero vertical dos registros varia de 12:2 a 26:6, o que pode distorcer a maioria das formas, mas, que por outro lado, amplia as feições não discerníveis por outros métodos acústicos.

Para a elaboração dos modelos tridimensionais do fundo dos fiordes e das partes subaéreas foram utilizadas cartas náuticas de escala 1:50.000 e 1:70.000 (Servicio Hidrográfico y Oceanográfico, Armada de Chile, 1996a, b e c; 1997). As cartas náuticas foram georeferenciadas, utilizando 0 software comercial ERDAS 32. As imperfeições geométricas foram corrigidas utilizando o polinômio de primeiro grau (linear) com quantidade mínima de 20 pontos de controle identificados na cartografia. Malhas (grids) foram construídas utilizando o método de interpolação Topogrid, com o software ARCINF0 3.2. Com o uso de softwares comerciais ERDAS 32, ARCINF0 3.2, ARCVIEW 3.2, GLOBAL MAPPER 6 foi possível interpolar as isóbatas, criar modelos 3D e perfis topográficos dos fiordes estudados, reproduzindo as morfologias subaérea e submarina.

A integração dos conjuntos de dados, acústicos e batimétricos, possibilitou a localização e a distribuição espacial no fundo marinho das principais fácies acústicas associadas aos depocentros de origem glacial. Esses modelos mostram a localização e a inferência sobre a extensão de ambientes erosivos e deposicionais, e provê um contexto regional para as interpretações das fácies acústicas e dos depósitos sedimentares.

\section{RESULTADOS \\ Morfologia submarina}

De acordo com os perfis topográficos Iongitudinais gerados a partir dos dados batimétricos, os fiordes são profundos e têm topografia irregular ao longo de seus perfis longitudinais. Os perfis topográficos refletem uma complexa morfologia submarina, que se mostra distinta não somente ao longo do fiorde como também de um fiorde para o outro. Sil/s ${ }^{1}$ localizados no interior e na saída de alguns dos fiordes geram múltiplas sub-bacias com profundidades variadas, as quais abrigam espessas seqüências de sedimentos estratificados.

0 fiorde Eyre apresenta um perfil que se inclina desde a cabeceira até a parte central do fiorde (Figura 2a). Desse ponto até o canal Icy, surge uma seqüência de bacias profundas, de $300 \mathrm{~m}$ de profundidade, aproximadamente, separadas por sills rochosos (em média, a $100 \mathrm{~m}$ de profundidade). Alguns desses sil/s correspondem a prolongamentos do relevo subaéreo dentro do ambiente marinho. A área de maior profundidade ocorre na confluência do fiorde Falcon, prosseguindo até 0 canal Icy, onde ultrapassa os $500 \mathrm{~m}$.

0 fiorde Falcon se distingue dos demais pela forma de platô na parte central de seu perfil longitudinal, onde se destaca um sill raso, a $90 \mathrm{~m}$ de profundidade, provavelmente de origem morâinica (Figura 2b). A localização desse sill coincide com a confluência de outro fiorde desde o sul e isola uma bacia interior, cuja profundidade alcança $400 \mathrm{~m}$. Os registros batimétricos e acústicos do fiorde Falcon começam na zona de inflexão em direção oeste, já que nas áreas próximas à cabeceira esse é ocupado por sikussaks (gelo marinho e icebergs aprisionados no interior do fiorde).

0 eixo central do fiorde Eyre, com aproximadamente $40 \mathrm{~km}$ de extensão até 0 canal Icy, se estende de forma quase retilínea até 0 sul. Os fiordes Falcon, Penguin e Europa correspondem a fiordes tributários desde o leste a esse grande eixo, seguindo a tendência de controle da topografia da cordilheira e de drenagem até os fiordes.

0 eixo longitudinal do fiorde Falcon em sua zona proximal é de SE-NW, o qual segue até a parte central, onde sofre uma inflexão para oeste, continuando assim em forma retilínea até a confluência com o fiorde Eyre e conformando no total $42 \mathrm{~km}$ de extensão (Figura 2c). Os fiordes Europa e Penguin ( $36 \mathrm{~km} \mathrm{e} 55 \mathrm{~km}$ de extensão, respectivamente) seguem a mesma tendência, porém com inflexões menos pronunciadas. Os fiordes Falcon, Penguin e Europa atuam como fiordes tributários e se localizam em níveis topográficos mais elevados comparados com o fiorde ou com 0 canal para 0 qual eles confluem, precipitando-se dois deles, os fiordes Falcon e Europa, sobre o fiorde Eyre e canal Wide, respectivamente.

0 fiorde Europa apresenta um perfil bastante irregular, com um pronunciado desnível topográfico desde sua zona proximal até sua área distal (Figura 4a). Em sua parte proximal um sill morâinico se destaca (Figuras 4a e b). Alguns dos sills, a partir da parte central do fiorde, correspondem em ambiente submarino, ao prolongamento de vales glaciais subaéreos, no sentido sul-norte. 0 fiorde Penguin, por sua vez, embora o gradiente de inclinação em seu perfil não seja muito pronunciado, se isola quase por completo do canal Wide por um conjunto de sills rasos (entre $30 \mathrm{~m}$

\footnotetext{
${ }^{1} 0$ termo em inglês sill é utilizado para as constrições topográficas submarinas transversais localizadas geralmente na saída dos fiordes, que interferem na circulação das águas entre esses e os oceanos. Podem ser de origem rochosa ou morâinica e também podem ocorrer ao longo do eixo longitudinal do fiorde, produzindo bacias semifechadas. Em espanhol, é empregado o termo umbral.
} 
a

FIORDE EYRE

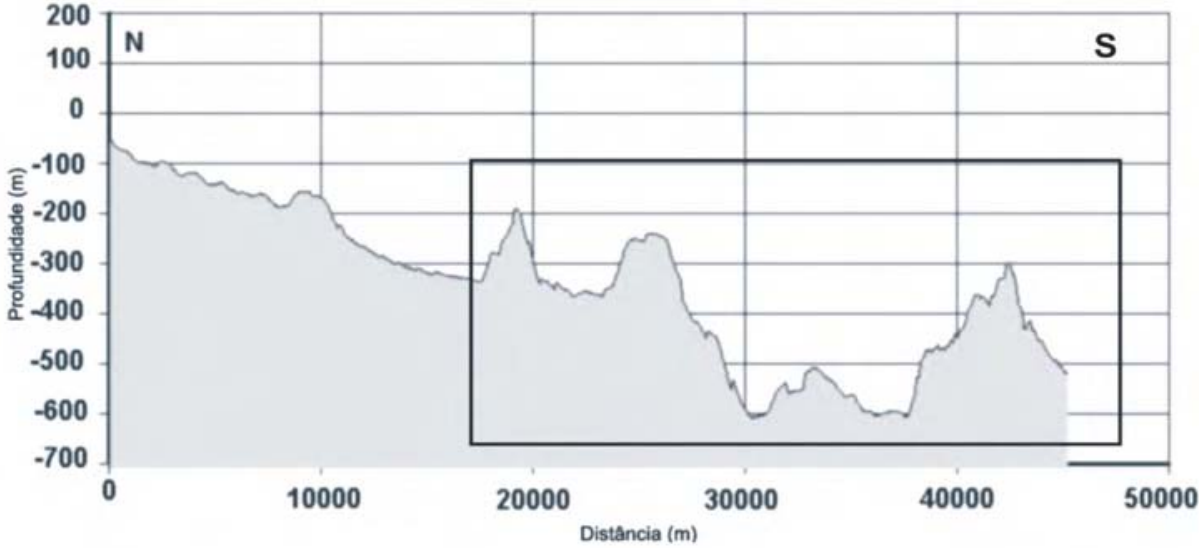

b

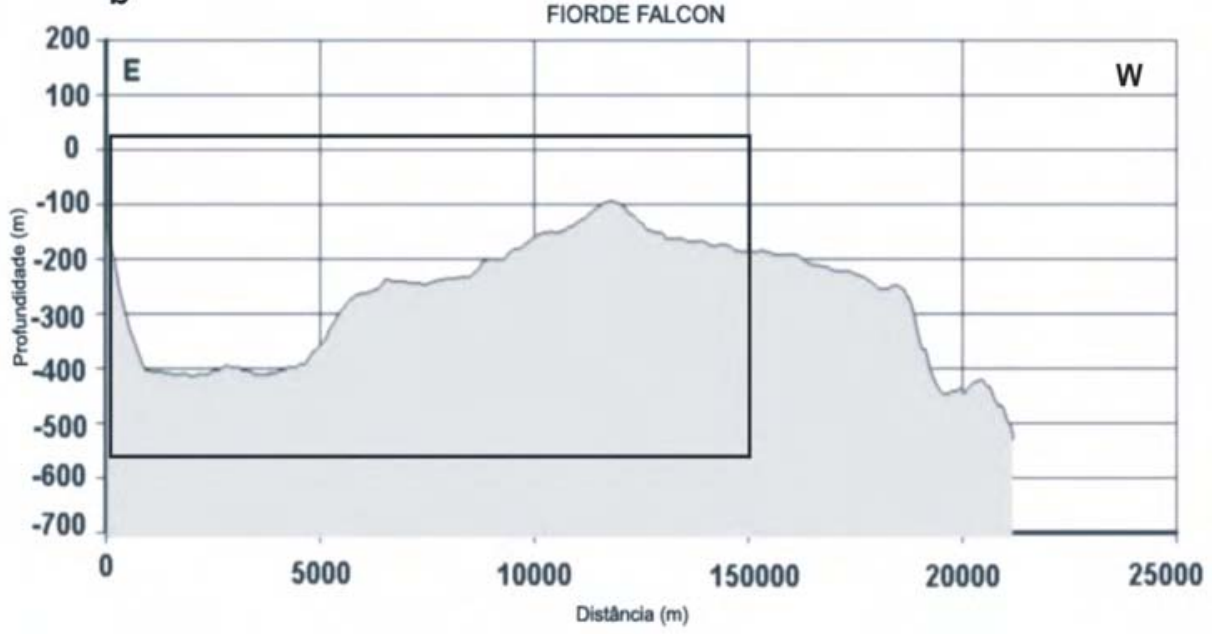

C

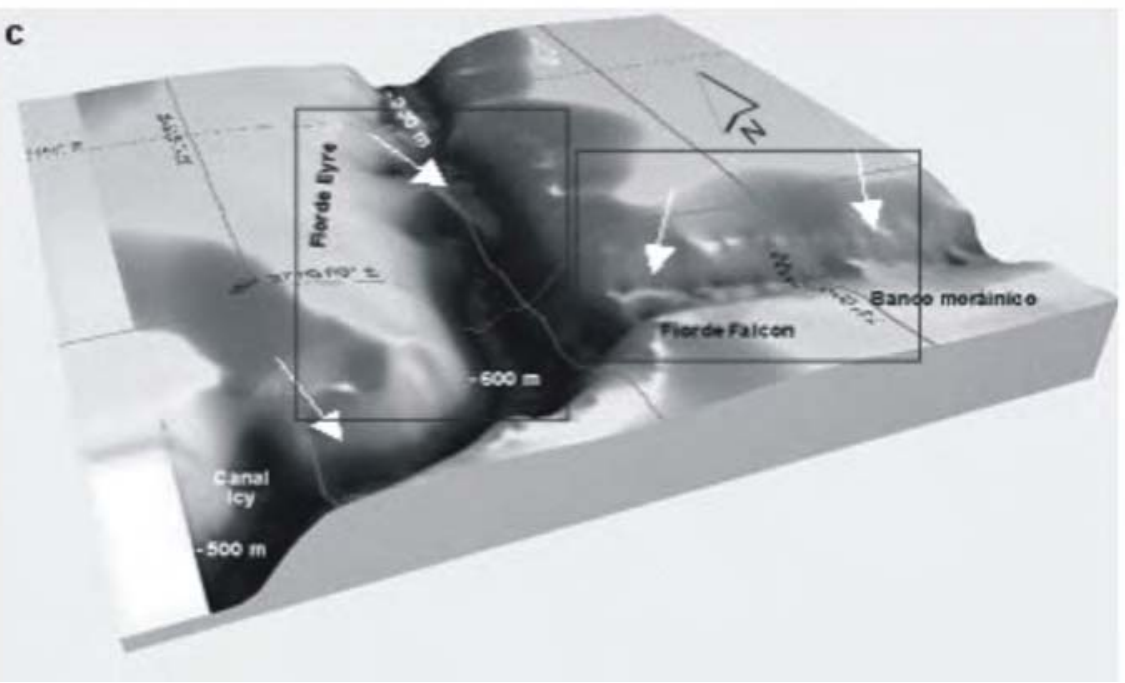

Figura 2 - Morfologia submarina dos fiordes Eyre e Falcon. Sills rochosos e morâinicos dividem o fiorde em várias sub-bacias (a). 0 fiorde Falcon é mais elevado do que o fiorde Eyre, precipitando-se sobre esse em uma zona onde a profundidade ultrapassa $500 \mathrm{~m}$ (a). A forma de platô, na parte central do fiorde, é marcada por um sill morâinico (b e c). Os retângulos nas Figuras a e b são localizados na Figura $\mathbf{c}$. As setas brancas indicam os sills. 


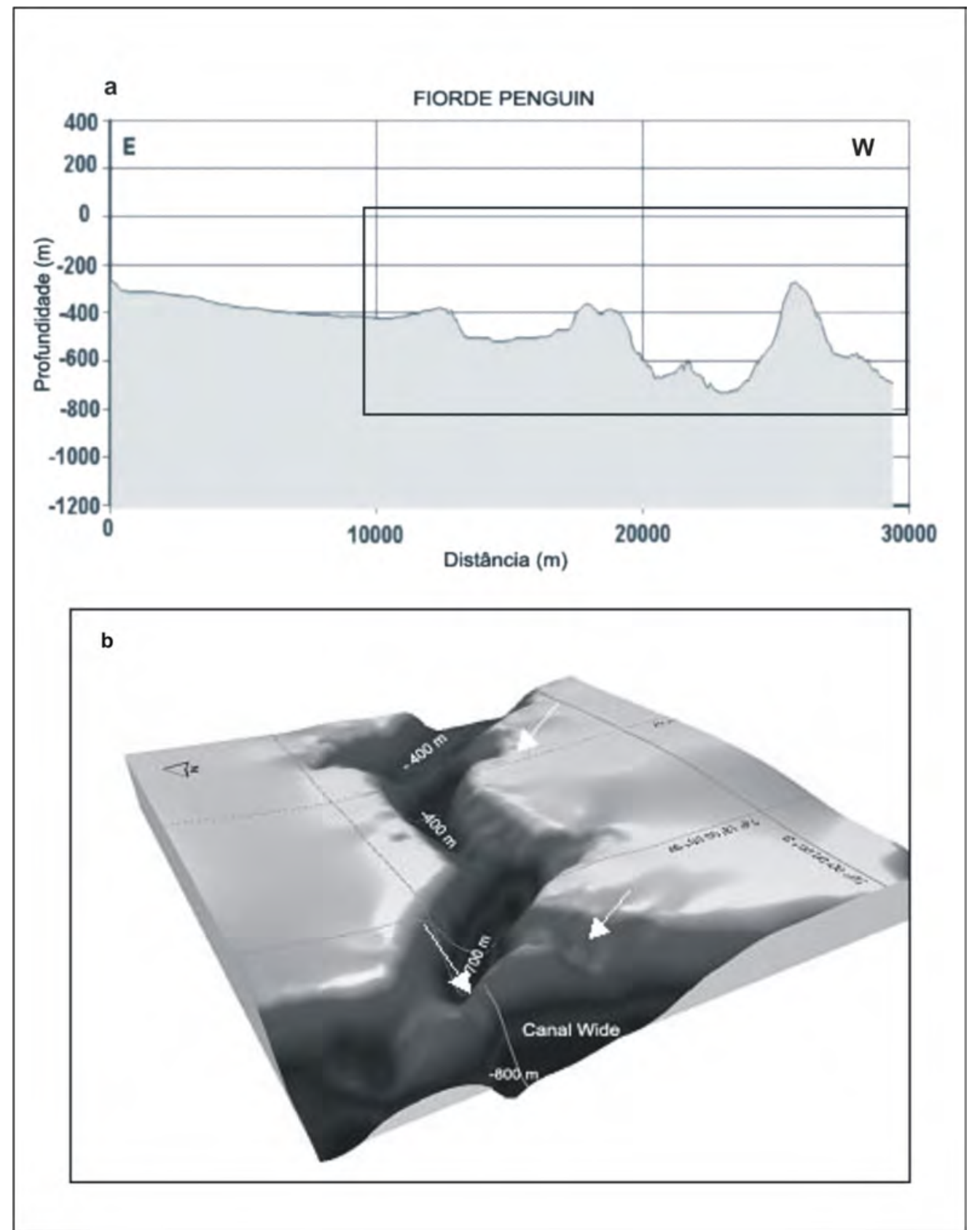

Figura 3 - Morfologia submarina do fiorde Penguin. Esse fiorde destaca-se pelas bacias internas separadas por sills rochosos e morâinicos (a e b), as quais são preenchidas por sedimentos estratificados. 0 retângulo na Figura a é localizado na Figura $\mathbf{b}$. As setas brancas indicam os sills.

e $50 \mathrm{~m}$ ), 0 que Ihe dá uma configuração de bacias fechadas, com profundidades entre 400 e $700 \mathrm{~m}$ (Figura 3).

Os fiordes Calvo e Amalia não tiveram seu perfis analisados por completo, pois 0 acesso às suas águas interiores estava bloqueado pelo gelo marinho. No entanto, a parte observada revela a presença de bacias internas separadas por sills, muito provavelmente, morâinicos. Os dois fiordes possuem sills na saída. No caso do fiorde Amalia, uma bacia não muito profunda de $150 \mathrm{~m}$, aproximadamente, é limitada por dois sills rasos, situados a $50 \mathrm{~m}$ abaixo do nível do mar (Figuras 5a e b). 0 fiorde Calvo possui 


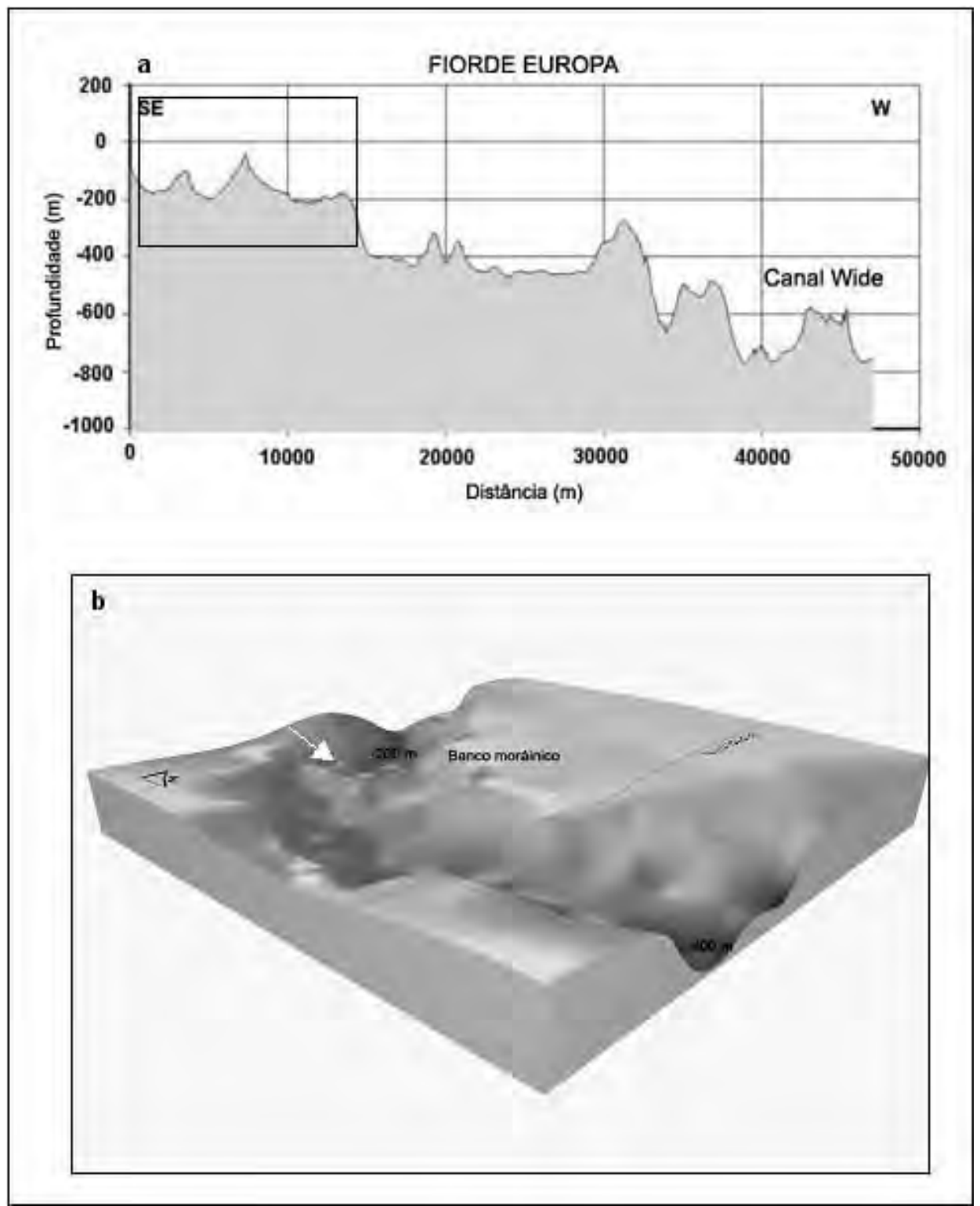

Figura 4 - Morfologia submarina do fiorde Europa. As bacias, com profundidades variadas, são separadas por sills, sendo a parte proximal do fiorde marcada pela presença de um pronunciado banco morâinico $(\mathbf{a} \in \mathbf{b})$. 0 retângulo na Figura a é localizado na Figura $\mathbf{b}$. A seta branca indica o sill.

uma bacia mais profunda $(340 \mathrm{~m})$, separada, na parte mais interna, por uma plataforma a $200 \mathrm{~m}$ de profundidade, e na saída do fiorde com a baía Chubretovich, por um sill a 80 metros abaixo da superfície da água (Figura 5c).

\section{Descrição das fácies acústicas por fiordes}

São reconhecidos distintos tipos de fácies acústicas nos registros de perfilador de subfundo $3,5 \mathrm{kHz}$ e essas estão distribuídas ao longo dos eixos longitudinais dos fiordes, no sentido cabe- ceira - saída. No entanto, predominam as fácies acústicas de configuração interna estratificada e caótica.

As fácies estratificadas apresentam configuração dos refletores internos paralela e subparalela, cobrindo comumente vertentes. Encontram-se também represadas em bacias internas. As fácies caóticas apresentam refletores internos desordenados das superfícies de reflexão, podendo indicar um ambiente de energia alta e variável, além de deformações contemporâneas ou posteriores à deposição. 


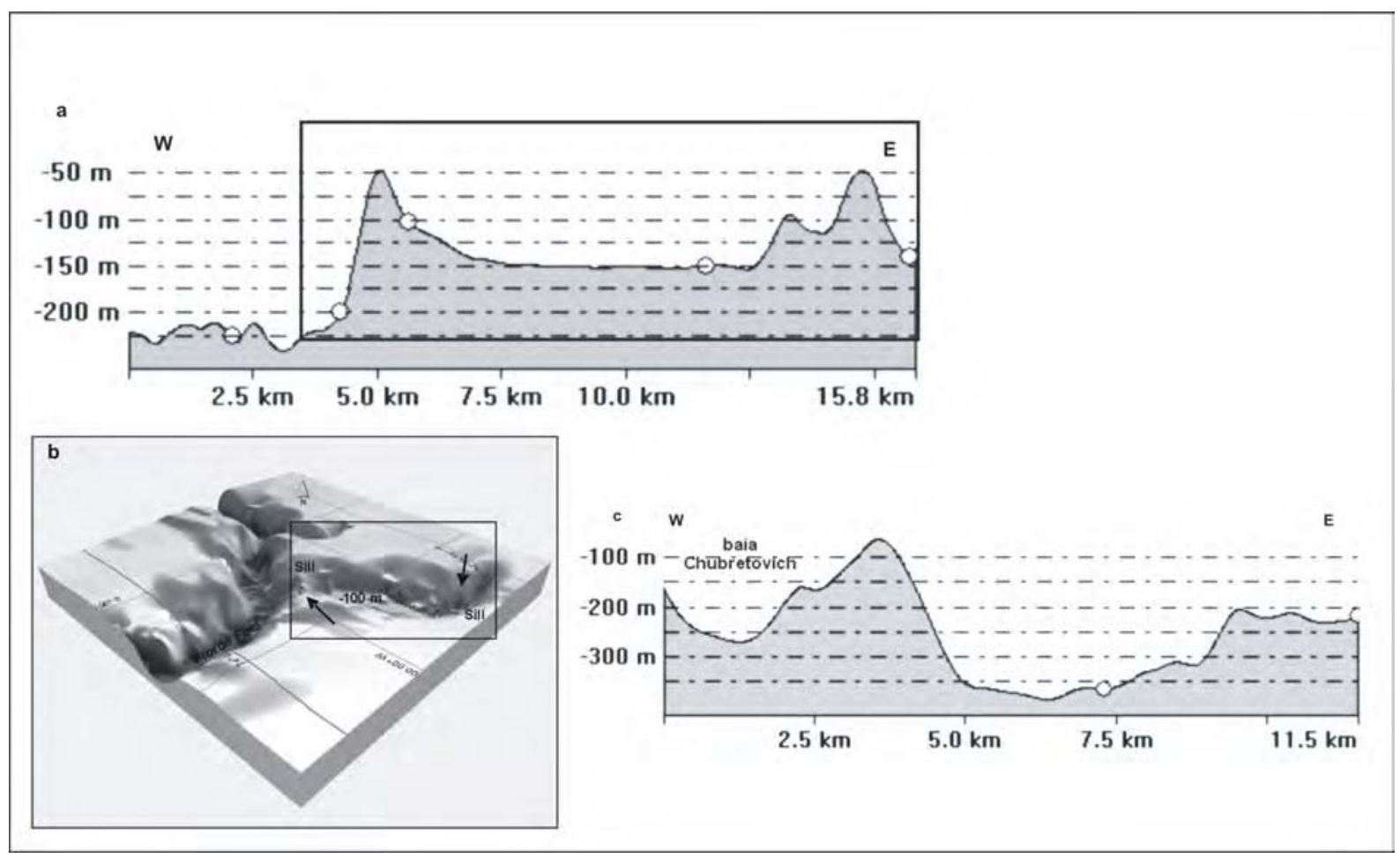

Figura 5 - Morfologia submarina dos fiordes Amalia $(\mathbf{a}$ e $\mathbf{b})$ e do fiorde Calvo (c). 0 retângulo na Figura a corresponde à área representada na Figura $\mathbf{b}$. A Figura c pode ser observada no retângulo da Fig. 11. As setas negras indicam os sills.

\section{Fiorde Eyre}

Nas zonas internas do fiorde, algumas bacias extensas apresentam seqüências sedimentares onde foram identificados dois tipos de fácies acústicas: estratificada e caótica (Figura 6a-c). A fácies estratificada, com refletores de subfundo de configuração paralela regular e continua, pode alcançar 8 metros de espessura, aproximadamente, em todo o seu conjunto. Essa fácies cobre em alguns setores a fácies caótica de configuração interna semitransparente a opaca no subfundo (Figura 6a). No mesmo registro a fácies caótica apresenta uma configuração progradante em forma de cunha, variando em espessura em $5 \mathrm{~m}$, aproximadamente. A progradação se dá em camadas sobrepostas que acompanham a inclinação da bacia para o sul.

Mais ao sul, nas bacias separadas por sills, as fácies estratificadas e caóticas exibem geometrias de preenchimento dos tipos sobreposto (onlap), sobreposto ondulado (mounded onlap ) e complexo, separados por sills rochosos e por fácies de configuração interna caótica e superfície hiperbólica (Figura 6b). Na profunda bacia observada na Figura $6 \mathrm{c}$ predomina a fácies caótica, a qual corresponde aos depósitos de atividade de vertentes, especialmente fluxo de detritos, que são reconhecidos por sua configuração acústica interna. No entanto, no fundo das bacias, 0 processo de preenchimento origina depósitos acusticamente laminados e caóticos.

A fácies estratificada possui sua maior espessura visível nas bacias da zona distal do fiorde, já nas proximidades da confluência do fiorde Falcon. Os estratos visíveis nesses pontos chegam a $20 \mathrm{~m}$ de espessura (Figura 7), e os refletores internos são múltiplos, contínuos, coerentes, paralelos e aproximadamente iguais em continuidade e em espaçamento.

\section{Interpretação}

No interior do fiorde, a fácies estratificada cobre a fácies caótica como no interior das bacias intra-sil/s. A fácies estratificada superficial, com 8 metros de espessura, aproximadamente, indica sedimentos finos.

$\mathrm{Na}$ Figura 6a é observado o caráter deformante das camadas estratificadas (superficiais) e das caóticas (subsuperficiais) por empurrão e compressão. A deformação em forma de cunha acompanha a pendente dessa parte do fiorde, refletindo maior deslizamento até uma barreira topográfica representada pelo sill. É importante acrescentar que tal zona de deslizamento compreende 


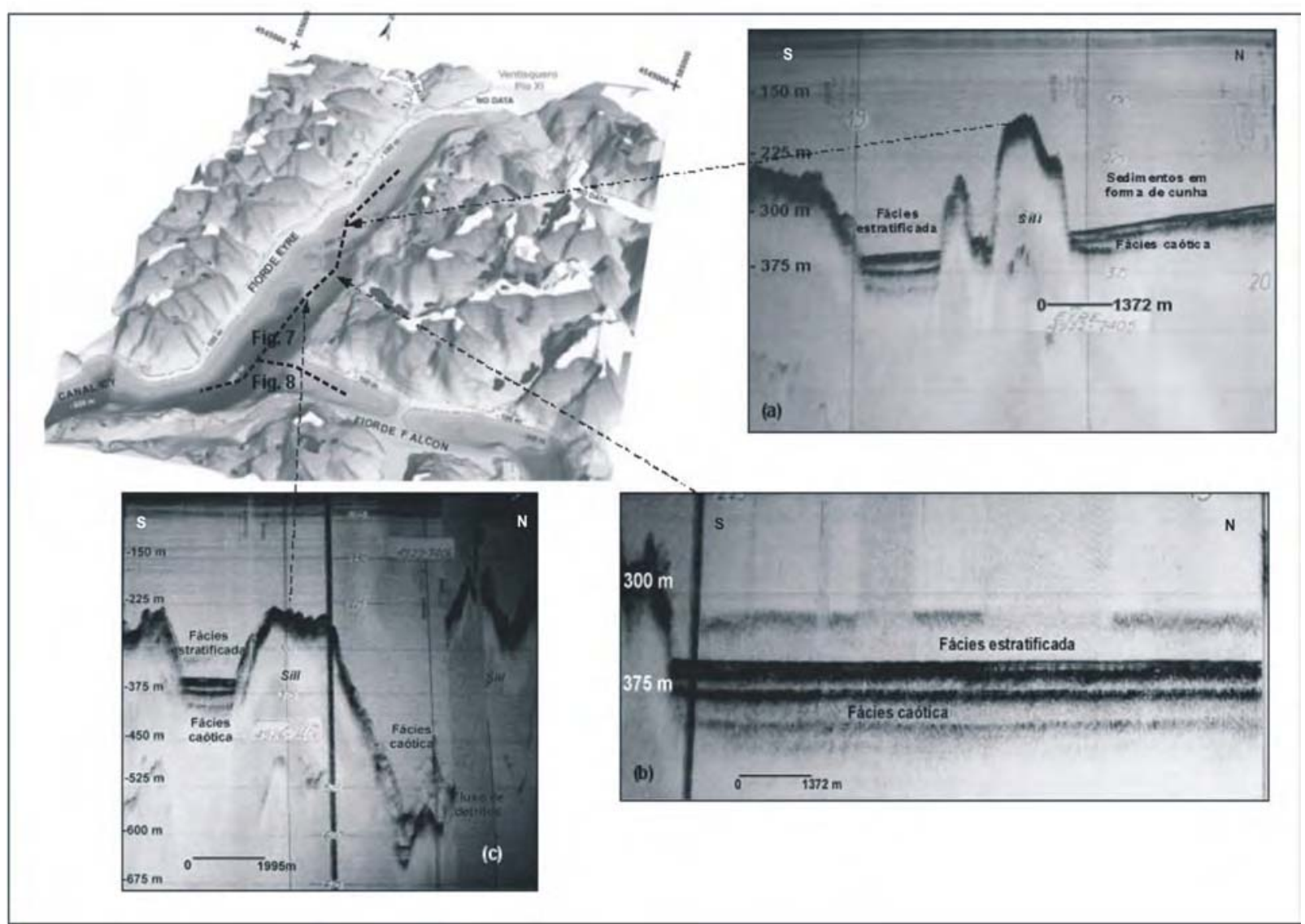

Figura 6 - Fiorde Eyre. Perfis acústicos da parte interior (a) parte central (b) e parte distal (c). Exagero Vertical = 18.3X (a), 18.3X (b) e 26.6X (c).

uma das áreas de estreitamento do fiorde, já referidas anteriormente. Portanto, esse processo pode ter sido causado tanto por possíveis sobrecargas devido a uma rápida sedimentação como por deslizamento vertente abaixo.

As fácies caóticas observadas na zona centro-distal do fiorde (Figura 7) são diferenciadas em dois processos genéticos distintos. Os fluxos de detritos e, inclusive, depósitos produzidos provavelmente por avalanchas se encontram próximo à base do sill rochoso com elevada pendente.

A forma identificada na Figura 7 como plunge pool se dá exatamente na base dessa classe de vertente onde se produz uma depressão, resultado de avalanchas e queda de blocos. Também é observado o deslocamento de sedimentos para a margem frontal da depressão e com deformação do corpo sedimentar, o que é uma outra característica atribuída a essa classe de forma.

Também na Figura 7, os bancos morâinicos são identificados segundo sua configuração interna caótica e a sua morfologia hummocky, que contrasta com a forte resposta dos refletores relacionados aos sills rochosos. A assimetria morfológica também identifica os bancos morâinicos, sendo a parte frontal do depósito menos inclinada e com atividade nas vertentes, identificada como fluxo de detritos. Na vertente posterior, orientada ao norte (interior do fiorde), a pendente mais forte se caracteriza pela perda de contato da frente da geleira com o depósito.

A estrutura das fácies estratificadas e sua localização, como são vistas na Figura 7, são indicativos de um ambiente proximal ao gelo, o qual recebe volumes de plumas turbadas de água de fusão que emergem desde as geleiras, além de sedimentos de fontes glaciais e subglaciais. Um banco morâinico separa as estruturas estratificadas. Tal feição sugere que essa fácies foi formada durante a retração da geleira, onde as elevações rochosas atuaram como ponto de fixação, proporcionando uma estabilidade temporal da frente do gelo. A assimetria morfológica dos bancos morâinicos (Cai et al., 1997; Seramur et al., 1997) sustenta a hipótese da etapa de retrocesso. 


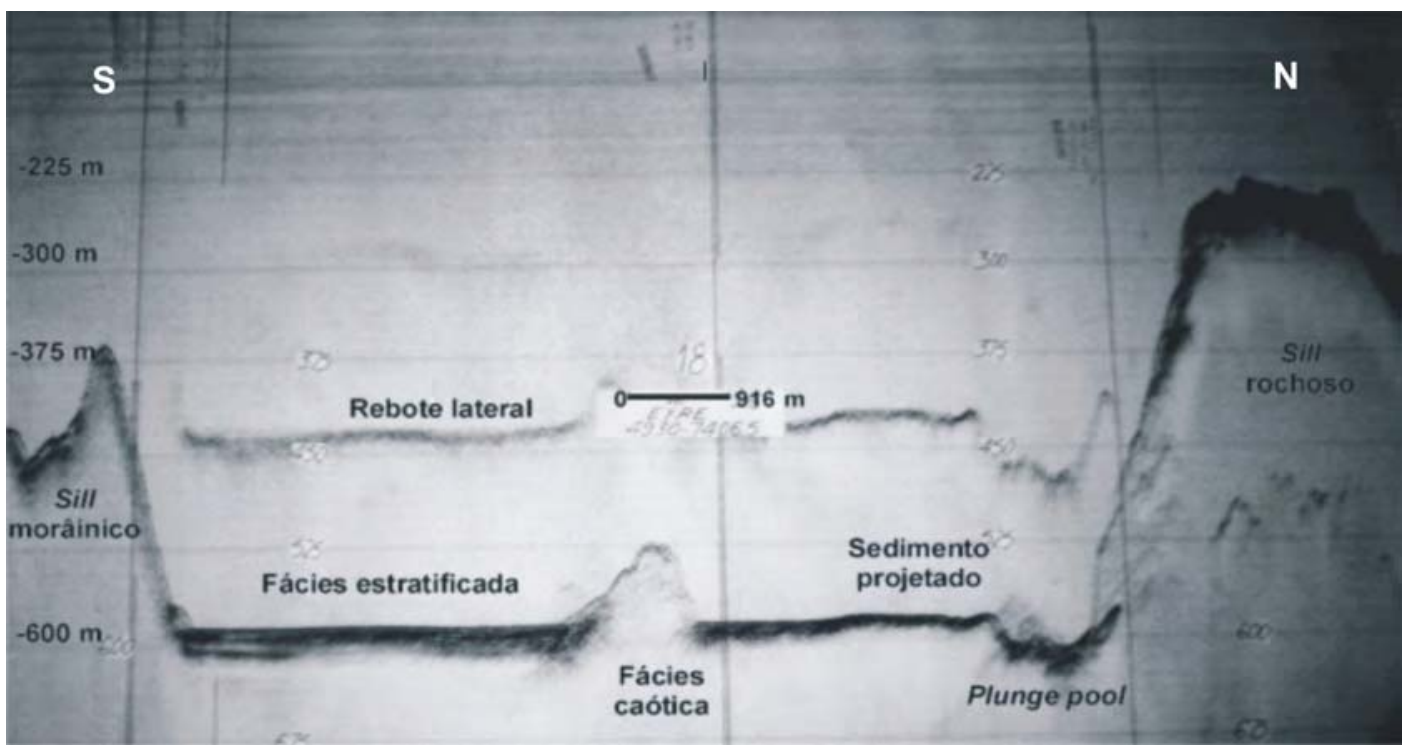

Figura 7 - Fiorde Eyre. Perfil acústico da parte distal. Exagero Vertical = 12.2X. A localização deste perfil pode ser observada na Fig. 6.

\section{Fiorde Falcon}

Na confluência do fiorde Eyre, entre 150 a 600 m de profundidade, são identificados três tipos de fácies genéticas: duas caóticas e uma estratificada (Figura 8). A primeira consiste de refletores internos caóticos fortemente refletidos em alguns setores, com aparente estratificação não paralela nas partes mais superficiais, difrações hiperbólicas e superfícies hummocky. A geometria externa não é uniforme e apresenta vertentes irregulares, quase verticais. A segunda fácies é de refletores acústicos internos não contínuos e opacos. São observados na base do sill, já no fiorde Eyre, e parecem formar uma sucessão de cunhas. A morfologia, em geral, é de uma cunha que diminui de espessura em direção ao exterior. 0 corpo principal do depocentro tem espessura visível de mais de 75 metros e as seqüências de cunhas, em torno de $15 \mathrm{~m}$.

Como o fiorde Falcon é um vale suspenso em relação ao fiorde Eyre, as duas fácies de configuração interna caótica estão separadas entre si por uma vertente de pendente muito elevada, e pela depressão já identificada como plunge pool. Da mesma maneira que no fiorde Eyre, essa depressão se desenvolve na base de uma vertente de grande gradiente, fruto do impacto de blocos e detritos desde as vertentes mais altas. Igualmente se observa 0 deslocamento de sedimentos para a parte externa da depressão, produzindo neles deformação.

A terceira fácies apresenta caracteres acústicos lenticulares, com refletores superficiais contínuos e precisos, a resposta interna é semitransparente e se sobrepõe à fácies caótica.

\section{Interpretação}

A fácies caótica, localizada entre 200 e 250 metros de profundidade no fiorde Falcon, pode ser interpretada como um cordão morâinico, devido à sua morfologia externa e feições internas, como também a pobre estratificação e a deformação dos sedimentos. Provavelmente, a litologia é formada por sedimentos grossos ou diamicto, baseado na elevada reflectância interna. Os processos de deformação podem estar associados às oscilações da geleira.

A segunda fácies de configuração caótica, porém com refletores mais opacos que os da fácies anterior, possui características de georformas integrantes do sistema de linha de encalhe (grounding line system). No entanto, sua grande profundidade dificulta tal interpretação, uma vez que exemplos dessa classe de geoforma são documentados em fiordes relativamente rasos (e.g., Cai et al., 1997). Se forem considerados os critérios de interpretação propostos por Seramur et al. (1997), poderia ser interpretada como uma forma deltaica, considerando sua geometria externa em cunha (wedge) e os refletores acústicos internos. A morfologia de cunha ou de um possível delta, a qual diminui de espessura nas partes mais externas, pode indicar diminuição de energia dos processos de transporte e de deposição. 0 depocentro, provavelmente originado por sedimentos em suspensão mesclados com depósitos de fluxos de gravidade desde a vertente, pode ser originário da margem com gelo aterrado no fundo, apesar da grande profundidade do fiorde nesse setor, o que não apoiaria essa interpretação. 


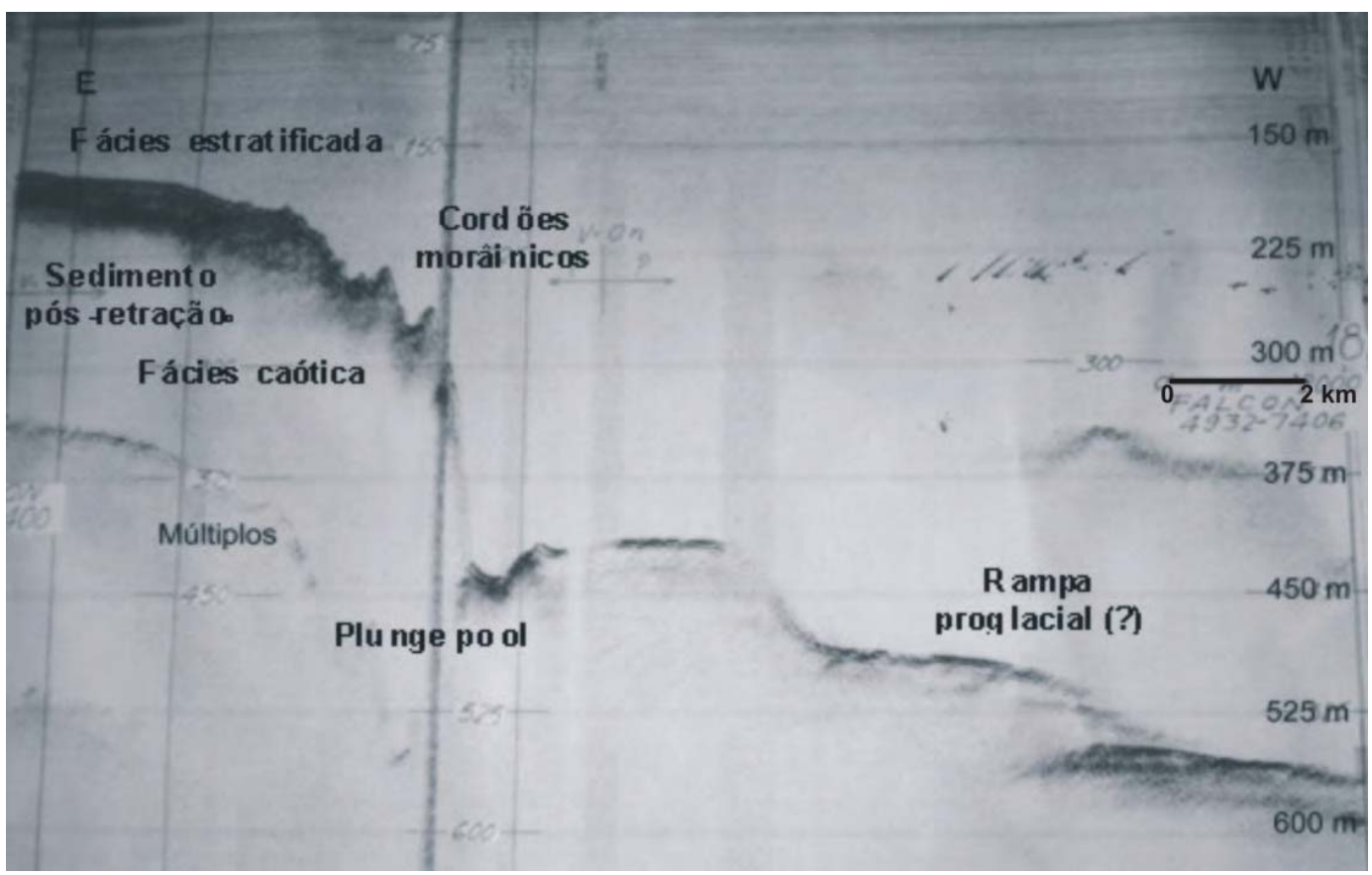

Figura 8 - Fiorde Falcon. Perfil acústico da parte distal. Exagero Vertical = 26.6X. A localização deste perfil pode ser observada na Fig. 6.

Uma segunda interpretação dessas fácies é baseada em Powell \& Alley (1997). A forma do depocentro corresponderia à classificação de rampa (ramps). Isso ocorre em uma zona de transição entre uma frente de geleira de maré e uma de frente flutuante; a uma curta distância de onde a parede frontal da geleira começa a flutuar é formada uma rampa de sedimentos à jusante da geleira. Para a sua formação, elas deveriam estar entre pontosfonte de descarga de correntes subglaciais da parede da geleira de maré. 0 pouco número de casos registrados consiste também em um problema para essa interpretação.

A fácies estratificada observada na superfície das vertentes pode ser interpretada como cobertura ou manto (drape) de material fino, tipicamente observado em ambientes de recuo de geleiras em fiordes.

\section{Fiorde Penguin}

0 setor centro-distal é o principal ponto de análise neste fiorde (Figura 9), nele são identificadas duas fácies. Uma corresponde a refletores internos caóticos, ligeiramente opacos, com difrações hiperbólicas e superfícies hummocky. A geometria externa, que se assemelha à da parte distal do fiorde Falcon, não é uniforme e apresenta vertentes irregulares, quase verticais. Nessa mesma zona também é identificada uma extensa área com pouca variação topográfica, cujos refletores internos têm de média a elevada re- flectância acústica. A fácies estratificada ocupa o interior da profunda bacia que é separada por sil/s rochosos, porém não contém estratificação regular e marcada. 0 padrão do refletor varia de muito preciso e coerente na superfície a semitransparente no interior. A configuração interna de preenchimento é do tipo sobreposto, cuja espessura visível alcança os $60 \mathrm{~m}$.

\section{Interpretação}

0 conjunto de fácies caóticas identificadas na Figura 9 corresponde morfologicamente a cordões de bancos morâinicos, e os depósitos proximais ao gelo se encontram em vertentes não estáveis, já que se identificam movimentos de massa. As pendentes mais fortes dos cordões indicam uma consolidação dos sedimentos. Os diversos cordões de sedimentos representados por essa fácies podem estar relacionados com as posições frontais da geleira. A zona com elevada reflectância interna poderia estar associada à diamicto massivo. No registro foram identificadas 5 prováveis posições da frente de gelo. A bacia profunda, localizada a oeste do sistema de linha de encalhe, capturou os sedimentos glacimarinhos, possivelmente quando o gelo estava flutuando nesse setor devido à grande profundidade, formando línguas de gelo, com fusão em sua base, propiciando dessa maneira os depósitos laminados. 


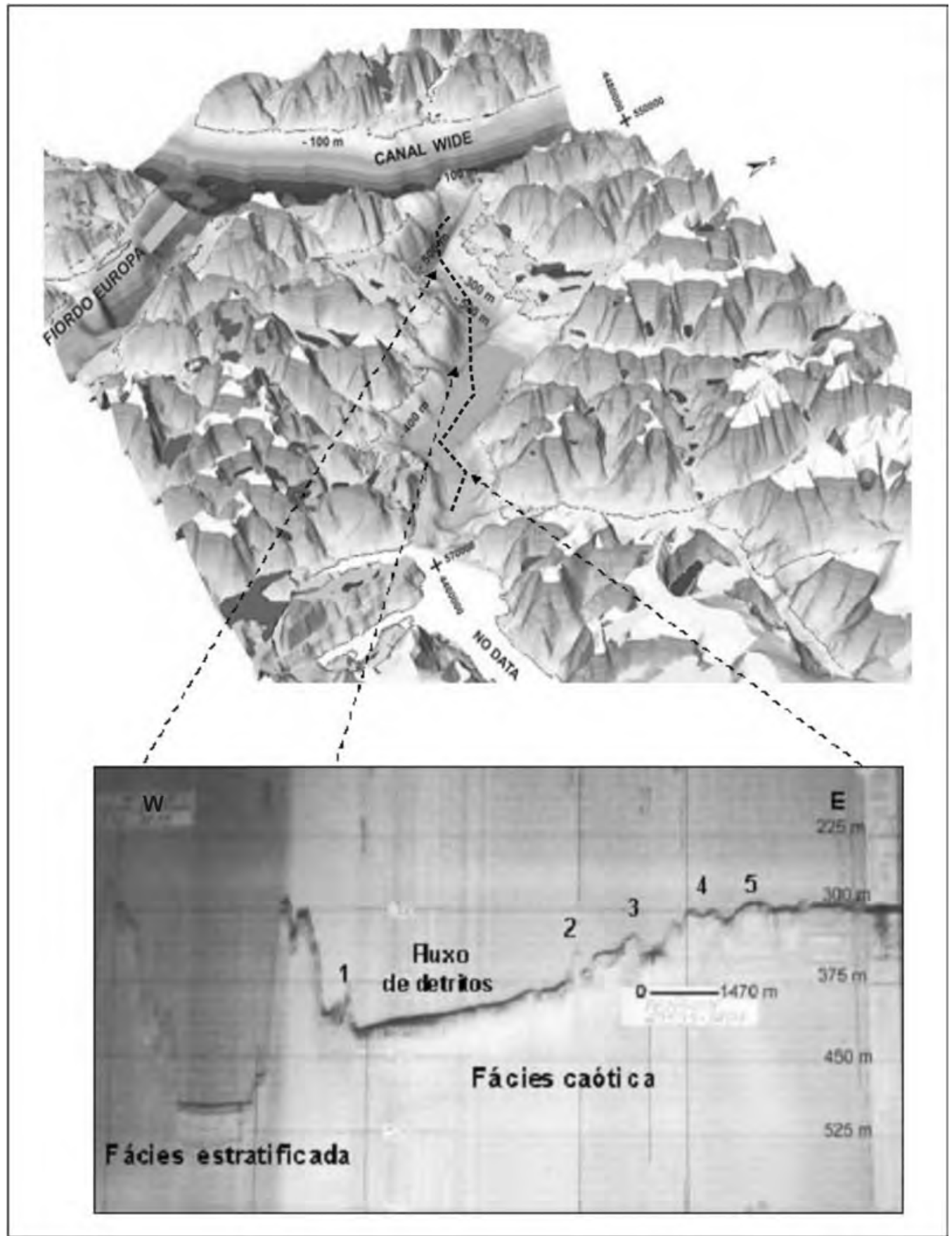

Figura 9-Fiorde Penguin. Perfil acústico da parte centro-distal. Exagero Vertical = 19.6X. As prováveis posições da geleira em um processo de retração estão enumeradas $(1-5)$. A linha segmentada representa a localização do perfil acústico.

\section{Fiorde Europa}

Três classes de fácies estratificadas e uma caótica foram identificadas (Figura 10). A última tem as mesmas características acústicas daquela encontrada no fiorde Penguin, porém as difrações hiperbólicas e as superfícies hummocky estão mais separadas entre si e intercaladas com a fácies estratificada I. Essa última sofre ligeiras deformações devido à pendente e à presença do corpo sedimentar de configuração interna caótica, que atua como uma barreira topográfica ao deslocamento basal dos sedimentos. 


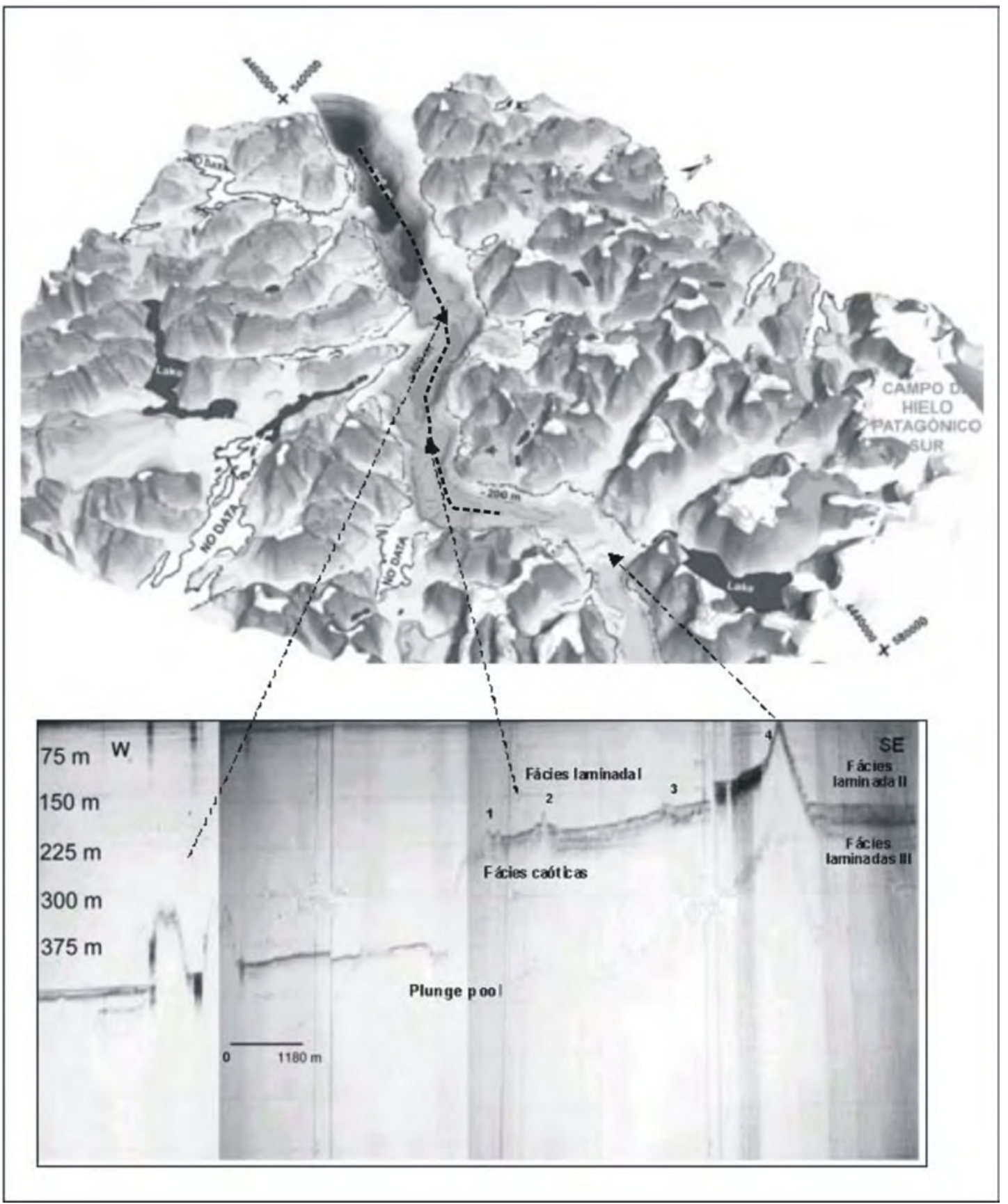

Figura 10 - Fiorde Europa. Perfil acústico da parte centro-proximal. Exagero Vertical = 15.7X. As prováveis posições da geleira em um processo de retração estão enumeradas $(1-4)$. A linha segmentada representa a localização do perfil acústico.

As fácies estratificadas II e III estão na direção montante, na posição anterior ao sill morâinico que se eleva a $35 \mathrm{~m}$ de profundidade, aproximadamente. As duas fácies possuem configuração interna regular, paralela, indicando deposição uniforme dos estratos. No entanto, os refletores internos da fácies II são mais precisos e coerentes que os da fácies III. A fácies II, que sobrepõe à fácies III, tem nessa parte do registro $25 \mathrm{~m}$ de espessura, aproximadamente, enquanto que à fácies subjacente possui cerca de $30 \mathrm{~m}$ de espessura. Junto ao banco morâinico é produzida uma deformação ou encobrimento de parte de suas camadas por fluxos 
de detritos oriundos da vertente interna do banco.

\section{Interpretação}

Tal como no fiorde Penguin, o fiorde Europa, em seu setor interno, apresenta características morfológicas e acústicas de um sistema de linha de encalhe. Nele, atividades nas vertentes, desde 0 banco morâinico, produziram depósitos de fluxo de detritos e de deslizamentos que acompanharam a vertente externa. Os depósitos de contacto com o gelo identificam duas posições possíveis da frente do gelo, além da posição de maior estabilidade da frente da geleira representado pelo sill morâinico raso, cuja espessura é superior a $70 \mathrm{~m}$. A crista do depósito está localizada cerca de $16 \mathrm{~km}$ da frente da geleira observada em 2001 pela imagem de satélite. As outras possíveis posições da frente do gelo, identificadas pelos depósitos menos desenvolvidos que a anterior, estão a 18 e $22 \mathrm{~km}$ daquela frente.

A fácies estratificada I, intercalada com os depósitos de fluxo de detritos, representa atividade das plumas de sedimento subglacial e depositada mais além das superfícies de contato com o gelo, composta de material mais grosso que foi possivelmente formada por fluxos de água de fusão subglacial, o que é indicado pelos refletores de configuração interna caótica.

As fácies estratificadas II e III podem representar dois processos genéticos distintos. A fácies III representa depósitos pósretração, quando a geleira recuou desde o banco morâinico para outra posição mais próxima à cabeceira do fiorde, ou possivelmente, para a atual posiç̧ão. Ao mesmo tempo, se acumulam os fluxos de detritos, desde a vertente interna do banco, originados do deslocamento das geleiras, e que se mesclam com os sedimentos estratificados. A fácies II corresponde a uma situação mais recente, representada pela deposição de sedimentos contidos nos icebergs e no gelo marinho retidos nas proximidades da cabeceira pela topografia do fiorde, formando uma extensa área dominada pelos sikussaks. 0 próprio banco morâinico pode operar como uma barreira à circulação livre do gelo para a parte externa do fiorde. Nesse sentido, os depósitos superiores estratificados seriam classificados como diamicto estratificado.

\section{Fiordes Calvo e Amalia}

Nos fiordes Calvo e Amalia, o gelo marinho não permitiu obter 0 levantamento das partes proximais à cabeceira. Ou seja, só foram investigadas as zonas de confluência do fiorde Peel, que são marcadas por sills rochosos e morâinicos cobertos ou preenchidos nas bacias mais superficiais por sedimentos estratificados.

As fácies caóticas no fiorde Calvo são caracterizadas pela ele- vada resposta acústica interna, porém incoerente. As camadas superficiais, que podem alcançar 30 metros de espessura, têm resposta acústica mais débil do que as camadas inferiores, que possuem em média 25 metros de potência visível de espessura. As camadas superiores diferem das subjacentes por sua forma de cunha, e a espessura diminui em direção à saída do fiorde (Figura 11).

No fiorde Amalia (Figura 12) a fácies caótica é representada pela média a elevada reflectância interna, refletores incoerentes e geometria hiperbólica da seqüência. No interior do fiorde, as fácies estratificadas ocupam bacias e atingem mais de $50 \mathrm{~m}$ de espessura visível de sedimentos. A camada mais superficial, com cerca de $9 \mathrm{~m}$ de espessura, compreende tanto refletores semitransparentes como transparentes caracterizados pela debilidade do sinal, com a estratificação visível a partir dos $10 \mathrm{~m}$ de espessura.

\section{Interpretação}

No fiorde Calvo são observados, pelo menos, três momentos de ação das geleiras. A localização dos sills na saída do fiorde indica a posição frontal da geleira; 0 banco morâinico aponta para uma posição de relativa estabilidade do gelo associada a um ponto de fixação; e, finalmente, o deslocamento de sedimentos em forma de cunha (lóbulo de detritos) revela um ambiente de progradação desenvolvido por uma outra posição terminal da geleira (dessa vez mais estável, devido à espessura do corpo sedimentar).

No fiorde Amália as distintas posições da frente da geleira podem ser inferidas pelos sucessivos bancos morâinicos, assim interpretados segundo suas características morfológicas e acústicas (Figura 12). As fácies estratificadas parecem corresponder, portanto, a uma fase mais moderna da deglaciação, com a fácies semitransparente relacionada a sedimentos mais finos, o que é comum nas partes distais dos fiordes.

\section{Morfologia dos fiordes e distribuição das fácies acústicas}

A profunda bacia do fiorde Eyre próxima à confluência do fiorde Falcon mostra controle significativo da topografia sobre 0 depósito sedimentar (Figura 7). Essa bacia está definida por uma barreira rochosa (em direção norte) e por um banco morâinico na saída do fiorde, já iniciando o canal Icy, o qual coincide com uma constrição topográfica. 0 depocentro no centro da bacia $(600 \mathrm{~m}$ de profundidade) igualmente coincide com outra constrição que está situada ao norte da entrada do fiorde Falcon e que atuou como ponto de fixação. A fácies acústica estratificada localizada ao sul 


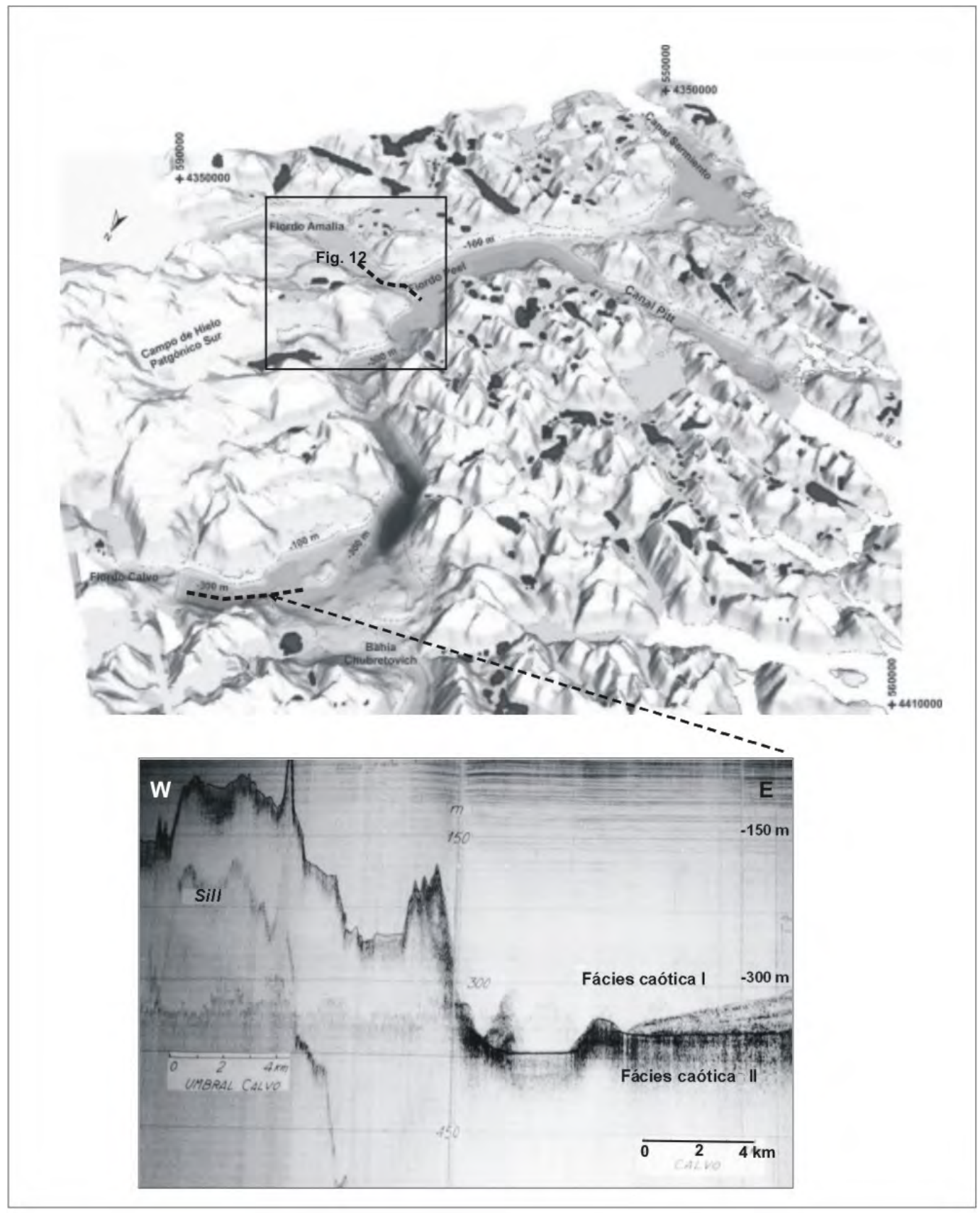

Figura 11 - Perfil acústico da parte distal do fiorde Calvo e baía Chubretovich. Exagero Vertical = 26.6X. 0 retângulo corresponde à Figura 5c e à Figura 12.

do banco morâinico é mais espessa que a do lado norte (30 m e $15 \mathrm{~m}$ de espessura, respectivamente, Figura 7). Isso pode indicar uma estabilidade relativa da geleira. Após perder 0 contato com o banco morâinico, a elevação rochosa foi seu próximo ponto de fixação. Tal ponto de apoio está efetivamente onde o fiorde se torna mais largo. A presença de plunge pool, observada vertente abaixo, indica movimentos de massa, provavelmente produto de uma pendente mais forte $\left(16^{\circ}\right)$ produzida durante a retirada do gelo.

A localização de um ponto de fixação na confluência dos fior- 


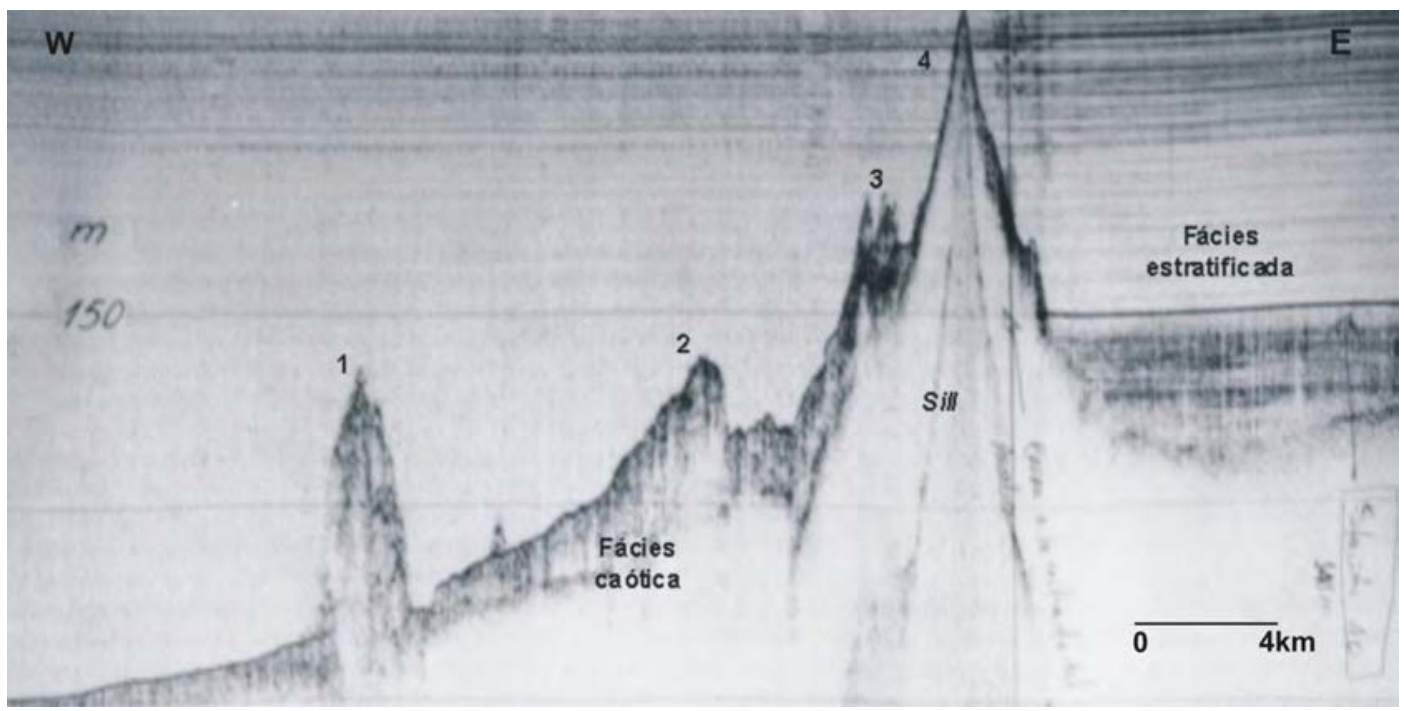

Figura 12 - Perfil acústico da parte distal do fiorde Amalia. Exagero Vertical = 26.6X. As prováveis posições da geleira estão enumeradas. A localização deste perfil pode ser observada na Fig. 11.

des Falcon e Eyre exibe duas classes de depósitos sedimentares produzidos em ambiente de linha de encalhe: os sedimentos formados (ou deformados) em cordões arqueados que ocorrem na saída do fiorde, desde 150 a $250 \mathrm{~m}$ de profundidade, e um amplo depocentro desenvolvido vertente abaixo, com cerca de $16^{\circ}$ de pendente, desde 450 a $600 \mathrm{~m}$ abaixo do nível do mar (Figura 8).

0 sistema de linha de encalhe se estende através da parte central do fiorde Penguin e está separado da bacia da parte distal (com profundidades superiores a $300 \mathrm{~m}$ ) por um sill, que corresponde a uma constrição submarina. 0 aparente leito acústico interno resultou de processos de fusão ou estava próximo a uma zona de atividade subglacial (Figura 9). No fiorde Europa, tanto 0 mais recente banco morâinico identificado nos registros, como os cordões morâinicos, se relacionam a pontos de constrição, e onde a profundidade e a largura do fiorde se reduzem (Figura 10). Nos fiordes Calvo e Amalia, depocentros se desenvolveram na saída dos fiordes e no interior, também coincidindo com constrições topográficas.

As fácies estratificadas são notavelmente intra-sil/s, em bacias profundas e em zonas proximais aos sistemas de linha de encalhe. No primeiro caso, dificilmente o gelo esteve em contato com o fundo, devido à grande profundidade. Portanto, a deposição dos sedimentos se deu através da fusão basal das línguas de gelo flutuante sobre esses pontos, e cobertas, posteriormente, por sedimentos mais recentes transportados pela deriva ao longo do eixo do fiorde.

As características dos registros acústicos e da morfologia dos fiordes sugerem posições de estabilidade das geleiras durante períodos de retração. Tais pontos de estabilidade seriam determinados pela geometria do fiorde. Nesses pontos, onde a área transversal diminui, se desenvolveram zonas de lavagem.

\section{DISCUSSÃO \\ Gênese das fácies acústicas}

Morainas - Os refletores acústicos identificados nos fiordes Falcon, Eyre, Penguin e Europa, Calvo e Amalia documentam bancos morâinicos nas bacias proximais e também nas partes distais. Através do perfilador de subfundo $3.5 \mathrm{kHz}$ essas geoformas submarinas apresentam principalmente configuração caótica e refletores internos incoerentes e de pouca penetração. Tais padrões de refletores acústicos são geralmente interpretados como sedimento de contacto com 0 gelo (till) (Syvitski \& Praeg, 1989; Cai et al., 1997; Seramur et al., 1997). No fiorde Europa (Figura 10) a margem estabilizada da geleira formou bancos morâinicos compostos de sedimentos de contato com 0 gelo acusticamente incoerente, que se mesclaram com sedimentos glacimarinhos acusticamente estratificados.

Rampas e lóbulos de detritos - Por meio da resposta acústica do perfil longitudinal, os processos sedimentares responsáveis pela origem da geoforma associada a uma rampa na confluência dos fiordes Eyre e Falcon podem estar relacionados a fluxos de água de fusão, fluxos de gravidade submarinos (ex. fluxo de detritos), assim como os processos subglaciais que 
atuaram na origem dos depósitos interlaminados, principalmente por suspensão de plumas de água de fusão. A aparência aplainada das rampas pode resultar da mescla de sedimentos finos glacimarinhos estratificados.

Pelo perfilador de subfundo $3.5 \mathrm{kHz}$, as feições acústicas dos lóbulos de detritos identificados na parte proximal do fiorde Eyre (Figura 6a) e na parte distal do fiorde Calvo (Figura 11) se mostram semitransparentes. A forma lobular pode corresponder a fluxos de diamicto. Em alguns fiordes onde ocorre esse tipo de geoforma é verificado que lóbulos de detritos podem compreender tanto de diamicto glacigênico como antigos sedimentos glacimarinhos retrabalhados (Elverhøi et al., 1983). Portanto, a deformação dos lóbulos indica que é mais provável ter havido transporte vertente abaixo por meio de empurrão de material subglacial, em um processo de avanço ou de surge, e também durante um período de estabilidade (Boulton et al., 1996), do que por processos de lavagem de sedimentos (Elverhøi et al., 1983).

Segundo Elverhøi et al. (1983), quando geleiras fluem para ambientes marinhos as forças de flutuação da massa de água e sedimentos glaciais brandos facilmente deformáveis tendem a reduzir a resistência de fricção basal, que é um condutivo para fluxos rápidos como os das correntes de gelo. Em muitos casos, tais áreas são propícias ao comportamento de pulsos de avanço (surging). Rivera et al. (1997) identificaram pulsos de avanços na geleira Pío XI, que provocaram a ocupação da parte norte do fiorde Eyre, interrompendo a comunicação das antigas cabeceiras com 0 restante do fiorde, transformando-se no atual lago Greve. A atual frente tipo tidewater da geleira está voltada para o sul do fiorde, próximo à confluência do fiorde Exmouth, enquanto outro tipo de frente desprendente (freshwater ca/ving) está voltado para o norte e represando o denominado Lago Greve (Warren \& Rivera, 1994). No entanto, seu regime pulsante não está ainda totalmente claro. Por isso, segundo Araya-Vergara (1999), é possível que a bacia interna do fiorde (que está parcialmente descoberta de registro sísmico) mostre feições específicas deste comportamento atíico de avanço, se comparado com os outros fiordes da região, que estão retrocedendo.

A identificação, portanto de algumas variedades do sistema de linha de encalhe (grounding line), como os bancos morâinicos, rampas apontam atividades sob condições de fluxo subglacial, que estão relacionados a um possível regime glacial temperado, com as frentes das geleiras aterradas no fundo marinho, como 0 sugerido por DaSilva et al. (1997).

Sedimentos acusticamente estratificados - Estão localizados em depósitos proximais ao gelo que estão mesclados com depósitos de contato com o gelo. São originados por plumas em suspensão emanadas da frente da geleira por atividade de fusão subglacial e por correntes de turbidez. Geralmente são sedimentos de granulação variada que vão se depositando de acordo com seu peso dentro da coluna de água (Cofaigh \& Dowdeswell, 2001). A presença de depósitos estratificados proximais ao gelo implica que os depósitos tiveram significante volume de água de fusão subglacial em seu sistema hidrológico basal, e, portanto caracterizado por um regime basal úmido ou politermal (Powell \& Domack, 1995).

As facies estratificadas que ocupam as bacias profundas nas zonas distais dos fiordes são associadas a sedimentos em suspensão, fusão basal das línguas de gelo flutuante e também por sedimentos transportados por icebergs (Cofaigh \& Dowdeswell, 2001).

As características apontadas acima sugerem que as fácies estratificadas se formaram durante deglaciação, quando elevações topográficas atuaram como pontos de apoio (pinning point) para as margens da geleira em retrocesso e facilitaram temporariamente a estabilização e a sedimentação proximal ao gelo nas sucessivas bacias.

\section{Topografia e geometria dos fiordes}

Evidências morfológicas e acústicas para relativas estabilidades das geleiras nos fiordes estudados revelam que a resposta glacial às variações climáticas pode ter sido influenciada em grande parte por sua geometria e morfologia. Em uma escala regional os fatores climáticos são os maiores controladores. As constrições topográficas e variações das profundidades atuaram como pontos de fixação (pinning point) para as margens das geleiras em retração e loci de subseqüentes depocentros, como o verificado em outros fiordes no mundo (Hunter et al., 1996; Seramur et al., 1997). Verificou-se que nesses fiordes adjacentes ao CGPS, em geral, os depósitos sedimentares correspondentes ao sistema de linha de encalhe (grounding line) estão associados a posições de estabilidade das geleiras que coincidem com localizações dos pontos de apoio (pinning points), além de variações de profundidade e largura do vale.

Feições acústicas dos depocentros indicam que alguns deles tomaram tempo para formar-se nas partes apoiadas no fundo sob condições estáveis, semi-estáveis ou inclusive de avanço. Bancos morâinicos, deltas de contato com o gelo se desenvolveram sob tais condições. Tal classe de depocentro está dispersa entre as constrições dos fiordes, dando espaço para os depósitos laminados. Em alguns dos casos, sedimentos produzidos na zona de 
linha de encalhe (grounding line) são acumulados e dão formas a elevações topográficas. Uma vez que retrocede de tais elevações, a geleira estaria exposta a um novo deslocamento até 0 interior do fiorde, como o ocorrido provavelmente nos fiordes Eyre e Penguin e no fiorde Europa (Figuras 9, 11 e 12).

\section{Profundidade das bacias}

Existem evidências geomórficas e acústicas de episódios de gelo aterrado no fundo dos fiordes analisados. A presença de sedimentos estratificados, próximo aos depocentros de refletores internos massivos e caóticos está vinculada aos vários tipos de sistemas de linha de encalhe (grounding line), como os bancos morâinicos e os deltas de contato glacimarinho.

Devido às grandes profundidades das bacias dos fiordes, a frente da geleira pode ter passado de flutuante para aterrado no fundo nesses pontos de fixação (pinning point) ao longo do fiorde. Possivelmente, durante a deglaciação nos fiordes, as geleiras estiveram aterradas no fundo quando alcançaram tais pontos e espessos depósitos de sedimentos se formaram junto às suas margens terminais, como os observados em alguns fiordes de grande profundidade na Noruega por Aarseth et al. (1989) e Aarseth (1997). Um rápido retrocesso pode produzir-se onde as bacias dos fiordes são muito profundas. No entanto, em ambas as situações, flutuante ou aterrado, as geleiras tiveram suficiente espessura para alcançar, embora por períodos não muito longos, esses pontos dos fiordes.

\section{CONCLUSÃO}

Este estudo integrou a sísmica de alta resolução e a morfologia submarina na interpretação do ambiente glacimarinho da costa de fiordes da Patagônia Central, Chile. Os perfis acústicos de alta-resolução (3,5 kHz) mostram que um complexo sistema deposicional com geoformas variadas desenvolveu-se nas profundas bacias nessa parte da costa de fiordes do Chile, a oeste do campo de gelo Patagônico Sul.

Foram identificados, baseado na morfologia externa e caracteres acústicos, depósitos de contato e proximais ao gelo associados ao sistema de linha de encalhe ( grounding line). Nesses estão incluídos os bancos morâinicos (isolados ou em cordões), deltas, rampas, lóbulos de detritos e sedimentos estratificados glacimarinhos, que foram construídos nos setores dos fiordes onde as partes frontais das geleiras puderam estabilizar-se por períodos suficientemente longos para o seu desenvolvimento. Esses depósitos estão, por sua vez, relacionados aos períodos de estabilidade e de possíveis avanços, que interromperam localmente o processo de retração das geleiras.
Dois tipos principais de fácies acústicas foram reconhecidos: as estratificadas e as caóticas. Os refletores acústicos estratificados se subdividem entre aqueles com traços coerentes, precisos, paralelos e contínuos, representando um período constante de sedimentação e naqueles menos precisos e contínuos. As fácies acústicamente estratificadas ocupam principalmente 0 interior de bacias intra-sil/s e áreas de depósitos proximais às antigas frentes do gelo, na zona de linha de encalhe. As fácies caóticas mostram-se incoerentes, variando de opacas a semitransparentes e, geralmente, com morfologia externa do tipo hummocky.

Os processos de deposição de sedimentos acusticamente caóticos ocorreram, possivelmente, durante períodos de retração das geleiras já no Holoceno, em pontos onde elas estabilizaram ajudadas pela morfologia dos fiordes, mesmo em águas profundas. Esses pontos de fixação (pinning points) tiveram forte influência tanto nos processos de estabilidade da frente das geleiras ao longo do Holoceno como na atualidade, com a formação dos sikussaks.

Os sedimentos dos depósitos acusticamente estratificados localizados nas bacias intra-sills e nas partes mais profundas originaram-se possivelmente de gelo flutuante, predominantemente de processos de desprendimento de icebergs (calving). No entanto, uma identificação mais precisa com respeito à origem dos sedimentos acusticamente estratificados será somente estabelecida através da aquisição de testemunhos de sedimentos e de registros sísmicos.

\section{AGRADECIMENTOS}

A CAPES, pela bolsa de Doutorado. Ao Servício Hidrográfico y Oceanográfico de la Armada de Chile pela disponibilidade das cartas náuticas e dos registros acústicos.

\section{REFERÊNCIAS}

AARSETH I. 1997. Western Norwegian fjord sediments: age, volume, stratigraphy, and role as temporary depository during glacial cycles. Marine Geology, 143: 39-53.

AARSETH I, LØNNE I \& GISKEØDEGAARD 0. 1989. Submarine slides in glaciomarine sediments in some Western Norwegian fjords. Marine Geology, 88: 1-21.

ANIYA M, SATO H, NARUSE R, SKVARCA P \& CASASSA G. 1996. The use of satellite and airborne imagery to inventory outlet glaciers of the Southern Patagonia Icefield, South America. Photogrammetric Engineering and Remote Sensing, 62: 1361-1369.

ANIYA M, SATO H, NARUSE R, SKVARCA P \& CASASSA G. 1997. Recent variations in the Southern Patagonia Icefield, South America. Artic and Alpine Research, 29: 1-12. 
ARAYA-VERGARA JF. 1999. Perfiles longitudinales de fiordos de Patagonia Central. Ciencia y Tecnología del Mar, 22: 3-29.

BOULTON GS, VAN DER MEER JJM, HART J, BEETS D, RUEGG GHJ, VAN DER WATERN FM \& JARVIS J. 1996. Till and moraine emplacement in a deforming bed surge - an example from a marine environment. Quaternary Science Reviews, 15: 961-987.

CAI J, POWELL RD, COWAN EA \& CARLSON PR. 1997. Lithofacies and seismic-reflection interpretation of temperate glacimarine sedimentation in Tarr Inlet, Glacier Bay, Alaska. Marine Geology, 143: 5-37.

CASASSA G, RIVERA A, ANIYA M \& NARUSE R. 2000. Características glaciológicas del Campo de Hielo Patagónico Sur. Anales Instituto de la Patagonia, Serie Ciencias Naturales, 28: 5-22.

COFAIGH CO. 1998. Geomorphic and sedimentary signatures of early Holocene deglaciation in High Arctic fiords, Ellesmere Island, Canada: implications for deglacial ice dynamics and thermal regime. Canadian Journal of Earth Sciences, 35: 437-452.

COFAIGH CO \& DOWDESWELL JA. 2001. Laminated sediments in glacimarine environments: diagnostic criteria for their interpretation. Quaternary Science Reviews, 20: 1411-1436.

DAMUTH JE. 1978. Echo character of the Norwegian-Greenland sea: relationship to Quaternary sedimentation. Marine Geology, 28: 1-36.

DAMUTH JE. 1980. Use of high-frequency $(3.5-12 \mathrm{kHz})$ echograms in the study of near-bottom sedimentation processes in the deep-sea: a review. Marine Geology, 38: 51-75.

DaSILVA JL, ANDERSON JB \& STRAVERS J. 1997. Seismic facies changes along a nearly continuous $24^{\circ}$ latitudinal transect: the fjords of Chile and the northern Antarctic Peninsula. Marine Geology, 143: 103-123.

DUCHESNE MJ, URGELES R, LONG BF \& LOCAT J. 2001. Geomorphology and slope instability features in the Outardes delta area, Quebec, Canada. Odyssée de la Terre, p. 371-378.

ELVERHØI A, LØNNE Ø \& SELAND R. 1983. Glaciomarine sedimentation in a modern fjord environment. Polar Research, 1: 127-149.

HUNTER LE, POWELL RD \& LAWSON DE. 1996. Flux of debris transported by ice at three Alaskan tidewater glaciers. Journal of Glaciology, 42(140): 123-133.

POWELL RD \& DOMACK EW. 1995. Glaciomarine environments In: MENZIES J. (Ed.). Glacial Environments - Processes, Sediments and Landforms. Boston: Butterworth-Heinemann, p. 445-486.

POWELL RD \& ALLEY RB. 1997. Grounding-line systems: processes, glaciological inferences and the stratigraphic record. In: Geology and
Seismic Stratigraphy of the Antarctic Margin, Part 2. Antarctic Research Series, 71: 169-187.

RIVERA A, ARAVENA J \& CASASSA G. 1997. Recent fluctuations of glaciar Pío XI, Patagonia: discussion of glacial surge hypothesis. Mountain Research and Development, 17(4): 309-322.

SERAMUR KC, POWELL RD \& CARLSON PR. 1997. Evaluation of conditions along the grounding-line of temperate marine glaciers: an example from Muir Inlet, Glacier Bay, Alaska. Marine Geology, 140: 307-327.

SERVICIO HIDROGRÁFICO Y OCEANOGRÁFICO, ARMADA DE CHILE. 1996a. Carta Náutica: Seno Exmouth, Eyre y Estero Falcon. Escala 1:50.000, Valparaíso, SHOA.

SERVICIO HIDROGRÁFICO Y OCEANOGRÁFICO, ARMADA DE CHILE. 1996b. Carta Náutica: Senos Penguin y Jarpa (Canal Wide). Escala 1:50.000, Valparaíso SHOA.

SERVICIO HIDROGRÁFICO Y OCEANOGRÁFICO, ARMADA DE CHILE. 1996c. Carta Náutica: Seno Europa. Escala 1:50.000, Valparaíso, SHOA.

SERVICIO HIDROGRÁFICO Y OCEANOGRÁFICO, ARMADA DE CHILE. 1997. Carta Náutica: Canal Pitt, Esteros Andrés y Peel. Escala 1:70.000, Valparaíso, SHOA.

STOKER MS, PHEASANT JB \& JOSENHANS H. 1997. Seismic methods and interpretation. In: DAVIES TA, BELL T, COOPER AK, JOSENHANS H, POLYAK L, SOLHEIM A, STOKER MS, STRAVERS JA. (Eds.), Glaciated Continental Margins: An Atlas of Acoustic Images. London: Chapman \& Hall, p. 9-26.

SUGDEN DE, HULTON NRJ \& PURVES RS. 2002. Modelling the inception of the Patagonian icesheet. Quaternary International, 95-96: 55-64.

SYVITSKI JPM, BURRELL DC \& SKEI JM. 1987. Fjords: Processes and Products. New York: Springer-Verlag, $379 p$.

SYVITSKI JPM \& PRAEG DB. 1989. Quaternary sedimentation in the St. Lawrence estuary and adjoining areas, Eastern Canada: an overview based on high-resolution seismostratigraphy. Géographie Physique et Quaternaire, 43: 291-310.

SYVITSKI JPM \& SHAW J. 1995. Sedimentology and geomorphology of fjords. In: PERILLO GME. (Ed.). Geomorphology and Sedimentology of Estuaries. Development in Sedimentology, 53: 113-178.

WARREN C \& RIVERA A. 1994. Non-linear climatic response of calving glacier: a case study of Pío XI glacier, Chilean Patagonia. Revista Chilena de Historia Natural, 67: 385-394.

WARREN C \& ANIYA M. 1999. The calving glaciers of southern South America. Global and Planetary Change, 22(1-4): 59-77. 


\section{NOTAS SOBRE OS AUTORES}

Rosemary Vieira. Graduada em Geografia (UFF/1986), Mestre em Geografia (Universidad de Chile/ 2002), Doutora em Geociências (UFRGS), e Estágio de Doutorado (Universidad de Chile / 2004-2006). Tem atuado nas áreas de Geomorfologia / Geologia Glacial e Geologia Marinha. Participou do cruzeiro de investigação científica CIMAR - FIORDO, junto ao Servicio Hidrográfico e Oceanográfico de la Armada de Chile, na costa de fiordes da Patagônia norte. Participa atualmente do Núcleo de Pesquisas Antárticas e Climáticas (UFRGS), onde colabora na investigação de ambientes glaciais da Antártica, junto ao Programa Antártico Brasileiro e Patagônia. Seus interesses de Pesquisa envolvem dinâmica de sedimentos e de ambientes glacimarinhos e glaciais subaéreos.

Jefferson Cardia Simões. Em 1990 foi o primeiro brasileiro a obter um Ph.D. em Glaciologia (a ciência da neve, do gelo e das geleiras) no Scott Polar Research Institute da Universidade de Cambridge (Inglaterra). É pós-doutor pelo Laboratoire de Glaciologie et Géophysique de l'Environnement, Grenoble, França. Professor do Departamento de Geografia da Universidade Federal do Rio Grande do Sul (UFRGS), onde coordena 36 cientistas no Núcleo de Pesquisas Antárticas e Climáticas (NUPAC). Este é um dos grupos de elite do Programa Antártico Brasileiro (PROANTAR). Pesquisador do Conselho Nacional de Desenvolvimento Científico e Tecnológico (CNPq), é o coordenador da rede de pesquisas "Antártica, as Mudanças Globais e as Conseqüências para o Brasil" do CNPq e do Ministério do Meio Ambiente, constituída por 15 instituições internacionais e em cooperação com outros 16 internacionais. 0 Brasil em vários comitês científicos internacionais, a destacar o Scientific Committee on Antarctic Research (SCAR), onde é o vice-delegado brasileiro. Participou da Operação Pólo Sul, junto com pesquisadores chilenos, sendo o primeiro brasileiro a atravessar a Antártica. 